\title{
TEACHING AND TRAINING
}

realising the potential of EU simulations - practical guidance for beginners

sandra kröger

Department of Politics, University of Exeter, Amory Building, Rennes Drive, Exeter EX4 4RJ, UK

E-mail: S.Kroeger@exeter.ac.uk

https://doi.org/10.1057/s41304-016-0096-1; published online 25 January 2017

\section{Abstract}

The benefits of simulation exercises easily outweigh potential weaknesses, and most of these weaknesses can be addressed by careful preparation. This article seeks to encourage instructors in higher education to embrace simulations as a means of encouraging active learning and greater retention as well as improving student and teacher satisfaction. However, there is not to date much helpful guidance, for first-time appliers, as to how to set up simulations. This contribution seeks to contribute to closing that gap by reflecting on the experience of two EU Council simulations that the author has organised. The aim is to openly review things that worked well and things that did not so as to allow colleagues interested in engaging in simulations in the future to see the reasons behind certain choices and perhaps avoid weaknesses of simulations set up by 'freshers'. In this context, articles are all too often presented as success stories, hiding errors or adaptations in the process, whereas in fact much can be learned from publically exposing and reflecting upon shortcomings and weaknesses of research and teaching design and processes. To finish up, some tips for 'freshers' have been compiled.

Keywords simulation; active learning; cooperative learning; European Union

\section{INTRODUCTION}

$\mathrm{n}$ higher education in general, and since the Bologna process started in particular, we can observe a move from instructor-centred teaching to student-centred learning (Guasti et al, 2015). The change more than anything involves the 
move from hierarchical forms of teaching in which the instructor talks and thereby seeks to pass on information and knowledge to forms of learning in which the students become more active and act as agents of their own learning processes, whereas the instructor becomes someone who moderates and supports these processes rather than being the centre-stage (Usherwood, 2014). In this context, one of the forms of student-centred learning that has increasingly attracted attention in political science is that of simulations, with the growth in the number of publications dedicated to simulations being reflective of this development (for EU-simulations only, see Zeff, 2003; Switky, 2004; Galatas, 2006; Kaunert, 2009; Jozwiak, 2012; Asal and Kratoville, 2013; Raymond and Usherwood, 2013; Usherwood, 2014, 2015; Brunazzo and Settembri, 2015; Fink, 2015; Jones and Bursens, 2015; Raiser et al, 2015). Indeed, in simulations, 'the classroom becomes an active learning center' (Zeff, 2003, p. 273). This contribution draws on this body of literature and reflects on my own experience of organising two simulations.

Simulations change the learning environment of students by allowing them to re-create an object of study. They are a recreation of a real-world situation 'designed to explore key elements of that situation' (Usherwood, 2014, p. 54). They allow students to fully immerse themselves in a concrete situation and thereby engage with it directly, rather than hearing or reading about it in the abstract. It is this active participation and immersion in the situation that enhances student learning (Jozwiak, 2012) by bridging the gap between thought and experience (Kolb, 1984). Learning here is 'actively constructed by the learner' (Jones and Bursens, 2015, p. 255). As a result, there is deep rather than surface learning which in turn results in greater retention of what was learned (Raymond and Usherwood, 2013, pp. 158-160). Additionally, a welcome side-effect is that students' motivation to
'...Organising a simulation can help students understand how the EU actually works. (...) Simulations also inject excitement and fun into the learning process and thereby make the EU a more accessible and interesting topic to study'.

learn can be increased by interesting them in a given topic through self-discovery, more autonomy and peer interaction.

It is not difficult to see why the EU, with its complex institutional set-up which is hard to understand even for established scholars, lends itself well to simulations (Brunazzo and Settembri, 2015, pp. 1-2). Organising a simulation can help students understand how the EU actually works (Zeff, 2003). It can help them appreciate, for example, that negotiations and compromise are of key importance and how the institutional set-up, as well as the power balance in them, importantly influences negotiation outcomes. Simulations also inject excitement and fun into the learning process (Switky, 2004, p. 40; Jones and Bursens, 2015, p. 255) and thereby make the EU a more accessible and interesting topic to study.

In order to explore the potential of simulations fully, it is important to properly design simulations and to prepare them well through a step-by-step process. Whereas there is a broad variety of publications addressing the potential gains in general, and describing some concrete simulations in particular, there is still a lack of suitable literature on the matter that serves as a meaningful guidance to those engaging with simulations for the first time (Usherwood, 2015, 
pp. 291, 221-22). Too often articles are presented as success stories, hiding errors or adaptations in the process. However, much can be learned from publically exposing and reflecting on lessons learned. In fact, choices about the design of simulations only become fully meaningful when confronted with alternative choices, and when potential advantages and disadvantages are openly discussed. This article seeks to provide precisely this kind of reflection and guidance by looking at two EU-related simulations I have organised and reflecting on what went well as well as what did not work. In doing so, I am fully aware that many of the related issues are contested in the interested community, and that each one of them could be and partly has been discussed at length. The ambition of this contribution however is different. It seeks to offer very concrete guidance and help to those instructors who would like to organise a simulation for the first time, but are not fully sure about where to start, how to set it up and what implications certain choices might have - as was the case for myself when I first started considering simulations.

The article proceeds as follows. Rather than discussing the potential advantages and disadvantages of simulations in the abstract, the article provides a step-bystep account of the two simulations I have organised so far and in doing so relates the individual points to the relevant literature, differentiating between choices that need to be made and actions that need to be taken prior to the simulation ("Preparing for the simulation" section) from the actual role play ("The role play" section). This will include highlighting and reflecting on what I learned from the first simulation and as a result changed in the second simulation, as well as noting where there is potential for further improvement. Drawing on my experiences so far, I will finally flag up a number of points to bear in mind when preparing
'...Too often articles are presented as success stories, hiding errors or adaptations in the process. However, much can be learned from publically exposing and reflecting on lessons learned'.

and organising a simulation ("Tips for successful simulations" section). The final section concludes ("Conclusion" section).

\section{PREPARING FOR THE SIMULATION}

Not having done a simulation, to get started I studied the literature on EU simulations and tried to find as much additional information about them in the internet as I could. I also talked to two colleagues in my department who had already organised simulations, all of which proved very useful and allowed me to familiarise myself with the theories behind simulations as well as their practical implications. However, none of this can replace the lived experience and the lessons reality teaches us, and I found that I learned at least as much from the real experiences as from the readings. Particularly, when organising them for the first time, one is well-advised to start preparing rather sooner than later as they are fairly time-consuming to organise. Exactly how much time in advance one should start is difficult to tell and will also depend on the learning objective of the simulation, its duration, the size of the group, the tasks students are given and therefore the time they need to prepare, etc. Concretely, one of the things one needs to look into early on is reserving appropriate rooms/spaces. I learned from

sandra kröger european political science: 172018 
the first simulation that one room plus the surrounding corridor was not enough, and so reserved two rooms next door to each other for the second simulation. Also, depending on who will choose the topic, one needs to give sufficient time to that. I proposed three topics to my students several weeks in advance of the simulation and made it possible for them to add topics of their choice until a given date. Once that date had passed, I let them choose between the available options through a secret ballot.

\section{CONTEXT}

The two simulations I organised comprised a group of 21 and 25 final year undergraduate students respectively who had chosen to take an optional two-term module I convene on 'Democracy in the European Union' at the University of Exeter. Students came from fairly diverse backgrounds - a third were international students - and typically had not engaged in a simulation before. This implies that the majority of them will have grown up in a fairly Eurosceptic country where it is easy to find misconceptions and lies about the EU on a daily basis. However, the fact that students took this optional module, indicates their interest in learning more about the EU. In the module and before the simulation, the students spend 12 weeks reading, discussing and researching different actors and channels of democratic representation in the EU, such as the European Parliament, national parliaments, Europarties and national parties, the European Council and the Council of the EU as well as nonelectoral actors. In other words, students should have a good overview over the functioning of democratic representation in the EU.

It is important to dedicate time prior to the simulation to explain to students how simulations work in general and what the specific one will be about. It is important to be clear about the set-up of the simulation, its limitations as well as possibilities, its learning objective(s) and the roles students would have and what is expected of them. It might be objected that this runs against the idea of active learning. However, one needs to take into account the environment in which a simulation is organised. In my case, this was within a context in which this kind of active learning is by no means standard, and where students are used to receiving fairly detailed information about their courses in general and assessments in particular. In other words, in my experience, year 3 students in the UK cannot be assumed to be ready to study and research independently of what they are asked to do. In such an environment, it is already quite an experiment to ask them to take their learning in their own hands. Indeed, I realised from the first experience that I had not given them enough guidance prior to the simulation and as such took this into account with the second simulation. However, even with this adjustment student feedback indicated that more time was required. ${ }^{1}$ In particular, it became evident that not all of them were aware that they needed a negotiation strategy from the start until the end so as to be prepared for different scenarios, to be able to adapt quickly to changing situations and to also to be capable of lobbying other delegations in the periods of informal debate. I will therefore devote even more attention to this in future simulations.

Finally, depending on what else is being taught in the module, one should also make sure that students have had at least one or two classes on the intended learning outcome(s) of the simulation. In this case, this related to how law-making works in the EU. Students should not be let into a simulation without any prior knowledge of the object of the simulation. I do agree that simulations can nicely complement, rather than replace more traditional forms of learning (Guasti et al, 
2015, p. 210; Brunazzo and Settembri, 2015 , p. 5). They depend on solid previous knowledge which in the present case will have been acquired through reading, reflecting and discussing the readings in class as well as research exercises in the foregoing 12 weeks of the module.

\section{LEARNING OBJECTIVE(S)}

Simulations can promote a variety of learning objectives, making it important to be clear to students about the objective(s) that should be achieved. This does not preclude that student learning goes beyond the defined learning objective(s), in fact this is rather likely. Still, identifying what students should learn in the simulation is crucial not just so that students know what the purpose of the simulation is, but also because it will influence decisions over which element(s) of reality can be simplified and which elements should remain as close as possible to reality. More concretely, simulations can be beneficial to three kinds of student learning: content, team and individual skills. I shall address the first (content) here, and the latter two at a later stage (under role allocation).

As regards content, it is claimed that simulations allow students to understand concepts, if not theories better (Jozwiak, 2012, p. 225; Asal and Kratoville, 2013, p. 134). With traditional lecturing these can remain fairly abstract. When illustrated in a role play, they become concrete and more understandable. For instance, by living through a concrete political process, students can understand better the need for compromise in politics why a given negotiation succeeded (or failed) or why a policy had a certain outcome rather than another. Content can thus refer to different things in a simulation - a concept, a theory, a process, an institutional design, a policy the sort of things political science academic publications typically address.
The learning objective that was most important to me in these simulations was content. Both simulations looked at the Ordinary Legislative Procedure (OLP), which is often studied in EU-related simulations (Raiser et al, 2015, p. 234). The primary learning objective was to convey a better understanding of the functioning of EU law-making, including the importance of compromise, in the EU. This might seem a rather vague objective. However, it made sense in the context of a module that had already covered a range of representative actors and later on addressed a number of contemporary debates and developments in the EU. The simulation helped students to better understand the challenges, difficulties and limits of democratic representation in the EU. It thereby helped them understand the material covered before the simulation better, and it likewise helped them to engage better with the topics of subsequent classes. While students obviously also learn something about the policy the simulation addresses, the details of that actual policy are not at the centre of attention. Instead, the topic serves as an example to illustrate how law-making works. However, since the topic obviously influences cleavages between Member States, those cleavages were taken into account in the selection of the represented states.

As regards the precise topic of the simulation, in the first simulation, students chose the Transatlantic Trade and Investment Partnership (TTIP), in the second they chose the refugee crisis in the EU. Neither simulated an existing legislative proposal. Instead, both were inspired by ongoing discussions and proposals, whereas the delegation representing the European Commission came up with its own legislative proposal, thereby giving students more ownership of the process and reducing the risk of them seeking to copy reality too closely. It became clear from the first simulation

sandra kröger european political science: 172018 
that not limiting the issue space of the topic proved overwhelming for students and detrimental to the learning objective. Therefore, to reduce the issue space of the topic, in the second simulation the legislative proposal was confined to a maximum of six articles. Students in the debriefing suggested this might still have been too much and a reduction of the number of articles could have made the simulation more manageable, a recommendation I will pick up next time around.

\section{DURATION OF THE SIMULATION}

The duration of a simulation, whilst being variable, normally ranges from half a day to a few weeks at most (see Brunazzo and Settembri, 2015, p. 3). There are two implications. First, real-world processes are evidently more complex than what the simulation can re-create. This is to do with the time span, the number of available actors, the availability of expertise, language (many as opposed to just one in the simulation). Likewise, simulations happen in a controlled environment (the classroom), whereas 'reality' does not happen in a comparable vacuum, and also has to take into account such issues as elections, public opinion and debates, as well as any unforeseen developments. As a consequence, only a small part of any given process can ever be simulated, and will therefore never achieve the same degree of complexity as the real process, thereby potentially creating a wrong image and reflection of reality (see also Guasti et al, 2015, p. 210). Second, we cannot expect to find the same degree of socialisation in a simulation as in reality. Many theorists, however, argue that socialisation processes importantly shape actors' behaviour in international settings, leading to adaptations of views and positions in the political process. I have found this to be an acceptable flaw of simulations, as long as one highlights and discusses these limitations with students - something I am aware I did not do enough of in the first simulation.

Originally I intended the first simulation to last one week, with some elements occurring before the classroom simulation, and then two hours of role play in the classroom. However, students liked it so much that it was decided to extend the simulation to another week. Looking back, I do think that running a simulation in just one week, with only a 2 hour meeting, is too short to deliver satisfactory results. The second simulation therefore was conceptualised as running over two classroom meetings, with other elements occurring both before the first meeting and between the two meetings. Whilst the choice of this duration is fairly subjective, it has proven to work well for the students, myself and the entire module. This is also indicated by the mean score of 4.17 (the range was from 1 to 5 , with $5=$ I totally agree) to the following item in the survey assessing the second evaluation: 'I feel I was able to participate actively throughout the two weeks of the simulation'. If students did not feel they could participate as actively throughout the two weeks as they might have liked to, then this was linked to two separate issues. First, they felt that the arrival of online contributions throughout the day was sometimes overwhelming (see below). It was suggested to limit the time for such contributions to a certain period of each day. Second, the simulation apparently took place in a period in which students needed to start working towards deadlines in other modules. In next year's simulation I will therefore move the simulation to an earlier point of the second term.

It must be noted that the simulation is only one part of a fairly long module (rather than running over the entire course), and the reasons why the chosen duration works well has a lot to do with how the module is organised overall and 
what other assessments students have to submit for this module. Running it longer would not work given a series of topics must be addressed in the module, both before and after the simulation, and that there also need to be enough available slots for students to do individual presentations. Running it shorter would not allow enough space and time for students to get into their roles, process interactions with their peers and learn from the experience. From my limited experience, it actually makes a lot of sense to not have the entire simulation in one single time-slot whether that is 2 hours, half a day or 1 to 2 days - but to organise it in sequences. The main reason is that it takes students a little while to get into the experience of role playing. Consequently, learning will be improved if they are allowed sufficient time to do so. But also, they might wish to look up additional information or try to informally lobby other delegations. Both are possible in reality - no piece of EU legislation is decided in just one afternoon and so giving students a bit of space to grow in the process only seems fair. Finally, students have to do other assessments both in this module and beyond it, and active participation in the simulation would likely drop would it last longer, at least if not counting more towards the overall mark.

\section{ASSESSMENT}

As regards the assessment of the simulation, there are two decisions to make. The first is whether or not the simulation should count towards the mark. This is a controversial issue in the interested community, with good arguments on both sides (Raymond and Usherwood, 2013). In my first simulation, because I felt too unknowledgeable myself about simulations and feared I might have made construction errors, I decided to not organise it as a compulsory element of
'...My experience is thus that students engage more seriously with the process when it counts towards the mark'.

the module nor to mark it. The implication was that three students pulled out and that even though students were engaged, they were less engaged than in the second simulation where the exercise was compulsory and counted towards the mark (20 per cent). My experience is thus that students engage more seriously with the process when it counts towards the mark. This was particularly, though not only, true in regard to the virtual communication before and in-between the two classroom meetings (see below). Whereas in the first simulation, the online communication basically did not happen, there was an amazing amount of online communication, over the period of two weeks, in the second simulation. Just how much the simulation should count will depend on how long the simulation lasts, what students are required to do, and what are the other assessments of the module. In practical terms this meant that I had three elements which counted towards the mark - a written report at the start of the simulation, the online communication with the other delegations over the two-week period (not the number of contributions would count, but their quality) and the actual participation in the face-to-face meetings of the simulation. As regards the latter, I made it clear to students that what counted was not that their delegation would be successful (as in getting its way), but the active engagement with the process.

The second decision is whether to assess students individually or in teams (in case one allocates them to teams as I do, see below). This is likewise a controversial issue (Raymond and Usherwood, 
2013). I opted for the latter, for two reasons. The first is that one of the intended learning outcomes of the module is that students learn to work in a team and that assessments need to be aligned with intended learning outcomes. Of course, this opens the box of freeriding and possible student discontent with that - indeed two students in their anonymous evaluation of the module made critical remarks in this direction. It is understandable that students can feel frustrated if their teammate does not contribute to the same degree. However, students need to learn to take responsibility themselves and also need to be prepared for their own later professional environment. Having potentially learned a practical lesson about free-riding and how to best address it is therefore actually an added value. My conclusion from the experience therefore is not to switch to individual assessment, but to raise the issue of free-riding explicitly and to make it even clearer to students, before the simulation, that it is their own responsibility, in their small team (of two), to make sure that both parts participate to a similar degree. The second reason is that some students can be fairly shy, therefore have less experience with speaking in front of a group, and as a result might be rather weak and scared delegations, if on their own. Giving them the opportunity to work in a team allows them to be part of the exercise and grow in a small team, where they will by definition have to communicate with their teammate. ${ }^{2}$

\section{ROLE ALLOCATION}

I allocated the roles to the students in both simulations, dividing them into teams of two. There are different reasons for that. They are linked to the other two forms of learning which I did not address above team and individual skills. As regards team skills, simulations create an interactive environment where students learn to work together, learn to negotiate, make compromises and form coalitions (Zeff, 2003, p. 269; Raiser et al, 2015, p. 231). In particular when working in small teams, they will become appreciative of the effects of positive interdependence which means that more can be achieved when working in a team than when working alone. Simulations also improve individual skills. They force students to develop their own view on a topic and defend it (Zeff, 2003, p. 270), thereby sharpening their ability to develop an argument and think critically. Because the argument needs to be defended, students also train their ability to speak freely, and in front of others (Zeff, 2003, p. 270). Students also learn to use their resources and time wisely, and to quickly adapt to unexpected circumstances or developments (Raiser et al, 2015, p. 231), such as an unexpected change in position of fellow actors in the simulation. Finally, (EU) simulations, because of their strongly interactive character and their dependency on compromise to work, allow students to appreciate different perspectives better and to also question their own behaviour (Raiser et al, 2015, p. 231).

Because these skills are not necessarily well developed with UK year 3 undergraduate students, I divided them in teams of two rather than allocating one role per student. Students feel more confident when not having to confront a new situation on their own and additionally can balance out their potential respective weaknesses. Having known the students for one term already at the time of the role allocation, I made up teams which were mixed in terms of their background (never two non-native English speakers in the same team) and in regard to their classroom performance so far (never two students who had both performed weakly so far). I furthermore inquired students' foreign language knowledge ahead of the allocation so as to also take that into account as much as possible (e.g. have 
students who can read German be part of the German delegation). In the simulations, these considerations and the way I implemented them seem to have worked fine.

The necessary roles for the simulations that I organised are those of Members of the European Parliament, of ministers in the Council, of the Presidency and of the European Commission. ${ }^{3}$ In the first simulation, I selected seven Member States which I thought relevant and representative of others for the selected topic, while in the second simulation I selected eight Member States along the same considerations. Knowing that I did not have enough students to cover all Member States, I thought it preferable to have a limited but representative number of states, but have teams of two, rather than delegations that would just be made up of one student each. I kept the 20/21 Member States which were missing constant by telling students in advance what their vote would be so that they knew beforehand how many more votes were needed to achieve the required double majority in the Council meeting if they wanted to pass legislation.

I also added 2-3 press representatives so as to add a public opinion dimension to the simulation. This is certainly open to debate. I thought it would contribute to the simulations being more realistic, as the press would put pressure on Member States' delegations in particular, which certainly happens in the context of important European legislative acts. This in turn would help students realise the often existing dilemma between domestic preferences and the need for compromise at the EU level better, a structural dilemma in European democracy. In the simulations, having press representatives actually worked really well - the respective students really enjoyed their role of interviewing political actors and drafted some amazing articles in very short time.

\section{THE ROLE PLAY}

In the simulations I have organised, students were asked to prepare reports of no more than two pages. The reports should indicate (a) the overall position of their allocated actor in terms of European integration; (b) the general position it has taken in regard to the policy that the simulation addresses and (c) the negotiation strategy it would endorse in the context of the simulation, including redline issues. These reports had to be drafted following the publication of the (fictional) Commission legislative proposal which was drafted by the respective delegation and limited to a maximum of six articles. The next team to draft its report was the team representing the Presidency, which based on the Commission proposal and the positions adapted by the Member States delegations, would lay out its position for the classroom simulation. The final 'reports' to come in were those written by the press representatives who I asked to draft an article both just before the simulations began as well as at the end of each meeting, first taking into account the reports by the other delegations and then reporting about the meeting itself. All the students sent their reports to me, and I uploaded them on the internet platform we use for teaching at Exeter, so that all students would have access to all reports ahead of the simulation. In fact, they were asked to read each others' reports before the classroom meeting and to likewise start communicating and negotiating with each other via the online forum, in specific forums that I set up for this.

The reasons for both tasks - writing reports ahead of the simulation and communicating with each other ahead of the classroom simulation - were the same, namely that students (a) would familiarise themselves with the position they would represent themselves and indeed 
develop it and (b) would familiarise themselves with the positions of the other delegations, so that they could actually develop a sensible negotiation strategy and contact potential allies ahead of the face-to-face meetings (Switky, 2004, p. 41). Both tasks also support students being prepared when the meeting in the classroom begins, which is a necessary condition for a simulation to run effectively (Jozwiak, 2012, p. 219).

One might object that the negotiation strategies displayed in the reports are confidential and that sharing them before the simulation and between students distorts reality. I disagree. In an organisation such as the EU, the positions of the different Member States are well known ahead of Council meetings in the respective ministries and permanent representations in Brussels. They are formed over long periods, years rather than months; they are taken into account in the legislative proposal by the European Commission, and no minister attending a Council meeting in Brussels will be surprised by the position or even negotiating strategy of another delegation. But also, and unlike in reality, in the context of the simulation students need to familiarise themselves in very little time with the position not only of their own delegation - or indeed develop it - but also with the positions of other delegations. Not sharing these reports and instead only discovering the positions of other delegations in the Council meeting would not only be unrealistic, but also prevent students from developing a realistic negotiation strategy ahead of the simulation and participating in the legislative process 'as it happens'. In other words, achieving the main learning objective, namely to improve students' understanding of law-making in the EU, would be endangered by overstraining what students should deliver during the simulation.

In theory, the online discussions based on the written reports started three days ahead of the first meeting. In reality this occurred to different degrees in both simulations (see the section on assessment above). In the second simulation where there was a lot of virtual communication, it was pointed out, when evaluating the simulation, that the amount of daily online contributions arriving into students' mailboxes had sometimes been overwhelming. Students therefore suggested to limit this communication to a specific time each day, e.g. 4-6 pm, so that it would become more manageable for them - a sensible recommendation in my view which I will pick up. Overall and comparing the degree of online participation in the two simulations - in the first practically none, in the second a great deal - using a virtual platform for a simulation in addition to the classroom play and 'forcing' students to use it can be very beneficial. It hugely supports students being better prepared as they are forced to familiarise themselves with the other delegations' positions early on, to develop and defend their own position, and to also try and seek compromise. In other words, it importantly helps them to get into the game as well as to develop the discussions between the two classroom meetings, so that discussions and consensus-seeking would not just pick up where they had ended in the first meeting, but, as in reality, would have evolved in the meantime.

The classroom meetings both times were a great success, with students really enjoying them. I asked them to dress in 'casual business' style, which allows them better to actually slip into their role. As pointed out above, in the second simulation I reserved two rooms for the two weeks, so that one would be available for the Council delegates to meet, whereas the other was reserved for the EP delegates, one Commission delegate as well the press. The simulation started with a brief 'tour de table' where all the national delegations would make a position statement and then the negotiations began. In 
the periods where the formal deliberations of the Council were interrupted, representatives of the Presidency, the Commission and the EP met in the conciliation committee to see whether a compromise could be reached. Meantime, the remaining delegations would use this time to lobby their peers informally whilst the press representatives would interview representatives and catch up with the development of the negotiations. After these periods of conciliation and informal debate, delegates of the conciliation committee informed their respective peers of the result of conciliation, and typically the legislative proposal would then go into the next reading, basically starting a second cycle.

Substantially, on both occasions the students managed to agree on some issues, whereas no consensus was found on others. As pointed out above, particularly in the second simulation, finding a consensus on some of the articles was greatly facilitated though the online communications that had preceded the meetings. In some instances, student behaviour seemed to be influenced by the desire to be nice with peers or at least not be perceived as difficult, but this is probably difficult to avoid entirely.

I limited myself to observing what was going on and to being available in case questions came up, whereas the simulation was moderated by the Presidency of the Council. I also took a number of pictures which students generally like as a souvenir, but which are also useful when communicating about the simulation later on (both years, I organised a news item on the politics website, which students really liked).

\section{DEBRIEFING}

It is important to set aside sufficient time for a debriefing after the simulation (Asal and Kratoville, 2013, pp. 138-139; Raymond and Usherwood, 2013, p. 163; Zeff,
2003, p. 272). Debriefings are important not only to find out about the degree of enjoyment by students, as well as learning effects and suggestions for improvement. They are also important to jointly discuss the process and results of the simulation and to make sure students realise which bits were rather realistic and which were not, as well as to allow for students to express both excitement and frustration. Upon reflection I did not sufficiently engage with the debriefing in the first simulation, likely because of my own insecurity as regards the construction of the simulation in the first place. As a result, the simulation perhaps remained a somewhat de-contextualised from the rest of the module, and I missed out on getting more feedback on how to improve the simulation. The second time around, I prepared the debriefing better, though I am aware there is room to improve further. On the one hand, I made a tour de table asking everybody what they had enjoyed, what they had found difficult and what the simulation had helped them understand better. I then related the responses back to the relevant theoretical debates that the simulation was supposed to bring into life. On the other hand, I had prepared a questionnaire in which I asked 14 questions relating to the learning of content, the preparation of the simulation, both by them and by myself, the degree of equal participation between team members, realistic student behaviour and their enjoyment of the simulation. I also asked whether there was anything they would recommend changing in future simulations. I realised later on it would have been good to spend even more time with the debriefing, particularly to further explain the missing parts of the simulation and how they had reduced complexity (Brunazzo and Settembri, 2015, p. 11).

Whereas I cannot, for lack of space, display all the answers and results of that evaluation here, the following provides an

sandra kröger european political science: 172018 
overview of the key issues. Overall students thought 'it was pretty cool and really helpful' and that 'it is a very efficient way of learning, you get to think more outside of the box'. Students also considered that they 'understood the theory in practice better, I could actually see what it looks like in real life'. On law-making, students agreed that they 'now have a much better grasp of how the process works'. They were also able to 'understand better how difficult it must be to actually pass legislation' and 'how difficult it is to come to an agreement'. Students also spoke about the fact that 'you can understand why it takes so long - there are so many barriers to overcome', and the simulation 'helped me understand how complex these issues are to solve'. As regards policies, students asserted that the simulation 'really helps people learn something about TTIP' and that they 'now have a much better knowledge of the refugee crisis when it comes to the EU'.

For the questions I asked students on the survey, I gave them a range of 1-5, with $1=\mathrm{I}$ totally disagree and $5=\mathrm{I}$ totally agree. Here are some of the results:

1. The simulation has increased my knowledge and understanding of lawmaking processes in the EU. 4.74

2. The simulation has sharpened my understanding of the importance of compromise, in EU policy-making. 4.52

3. The simulation has increased my knowledge of the current EU refugee crisis and how selected Member States address it. 4.60

These are very good and encouraging results. They are outstanding insofar as the main learning objective of the simulation is concerned, namely for students to better understand EU law-making, including the importance of compromise. They are likewise very high as regards increased knowledge of the concrete policy under study. At the same time, however, a
'Overall students thought 'it was pretty cool and really helpful' and that 'it is a very efficient way of learning, you get to think more outside of the box'. Students also considered that they 'understood the theory in practice better, I could actually see what it looks like in real life".

degree of care has to be taken in terms of the assessment of such evaluations and that students assessment of the simulation and their own learning process might vary depending on when the assessment takes place, such as immediately after the role play or at a later date. However, making the assessment an exact science does not interest me. If they as well as the instructor consider the simulation has improved their understanding of, for instance, EU law-making, as also indicated in the quality of follow-up discussions, then a lot is gained. And whilst the 'real' learning effect might be lower if somehow measured 'objectively', I would still trust that if students consider they have learned something due to the simulation, something they had previously less understood, then that is actually the case. If in addition students enjoy learning through simulations, as indicated by the likewise extremely high score of 4.61 to the item 'I enjoyed the simulation', then what else can one hope for?

\section{TIPS FOR SUCCESSFUL SIMULATIONS}

There is not one single way to run a simulation (Asal and Kratoville, 2013, p. 136). How to set it up depends on the aims of the simulation and the number of 
participants, amongst others. However, they do need to be well-designed to achieve their aims (Brunazzo and Settembri, 2015, p. 5). Also, simulations cannot replace prior knowledge of the topic to be studied, but seek to deepen existing knowledge (Guasti et al, 2015, p. 208). On this basis, and summing up what has already been said so far here are some tips as to what to bear in mind when organising a simulation:

1. When preparing a simulation: talk to colleagues who have already done simulations; decide first what the learning objective is and then how to set up the simulation; reduce the issue space to a manageable size; make sure you have the space(s) and possibly technology you need; spend sufficient time, prior to the simulation, explaining to students what the learning objectives are, what the structural limitations are and how reality as a result gets reduced, as well as how the simulation broadly should run; make it clear to students that good preparation is key; have the simulation count towards the mark - the effect will be greater student engagement and therefore a better simulation overall.

2. During the simulation: allow enough time - learning is a process and students will likely learn more if the entire simulation is not just packed into one session, but a process of several steps/ meetings; use an internet platform, both for making available relevant information and possibly for students to use for their negotiations before and in-between the class meetings; restrict yourself to being an observer during the simulation - it is okay for students to make errors - and to being available in case questions come up.

3. After the simulation: allocate enough post-simulation time for a debriefing, both to get students think about the
'...Even disagreeing with the tips should be helpful when making different decisions as the implications of the latter should now be clearer'.

outcomes and relate them back to theory and also to learn about what they thought went well and what did not.

\section{CONCLUSION}

In this contribution, I engaged in a detailed review and reflection of the two simulations I have so far organised, linking my experiences to relevant literature on the way. The aim was to openly review things that worked well and things that did not so as to allow colleagues interested in engaging in simulations in the future to see the reasons behind certain choices and perhaps avoid weaknesses of simulations set up by 'beginners'. Finally, I have listed a number of tips for 'beginners' which will hopefully be helpful and encourage even more colleagues to engage in simulations. Whilst one might disagree with some of these tips, the reasons driving them have hopefully become clear as well as the implications of alternative choices. Therefore, even disagreeing with the tips should be helpful when making different decisions as the implications of the latter should now be clearer. Obviously, some of the lessons learned relate to my specific context and will vary from context to context, such as when in the module is the simulation best placed, how much simulation-related teaching do students need prior to the simulation, how much guidance overall do students need, whether one should allocate roles or let students pick the roles themselves and whether or not students should be allocated to teams. Other 
lessons are more universal, such as the importance of defining the learning objective well, of limiting the issue space or of having the simulation count towards the mark. Overall, the benefits of simulations, in my view, easily outweigh potential weaknesses, and many of the weaknesses can be addressed by a careful preparation and debriefing. Yes, simulations are time-consuming, but they are really rewarding in terms of student engagement, team as well as individual learning, student satisfaction as well as teacher satisfaction as you see your students grow in the process.

\section{Notes}

1 When students evaluated the simulation in the debriefing (see below), 4.21 was the mean score (of a range from 1 to 5 , with $5=$ I totally agree) for the following: 'The module convenor provided sufficient information ahead of the simulation to get started'. Whilst still a high score, it was amongst the lowest in the survey assessing the simulation.

2 In British Universities, there are the so-called Individual Learning Plans (ILPs) which students might receive from the University as a result of having a specific health condition. One thing the ILP might state is that one should not individually address the respective student in class, e.g. because of anxiety issues. As a result, such a student could in fact opt out of the simulation all together if she or he was on their own, whereas being part of a small team removes the issue and allows the student to participate.

3 Because of the limited amount of students, both the European Parliament and the European Commission had to be represented as unitary actors.

\section{References}

Asal, V. and Kratoville, J. (2013) 'Constructing international relations simulations: Examining the pedagogy of IR simulations through a constructivist learning theory lens', Journal of Political Science Education 9(2): 132-143.

Brunazzo, M. and Settembri, P. (2015) 'Teaching the European Union: A simulation of council's negotiations', European Political Science 14(3): 1-14.

Fink, S. (2015) '36 different chocolate directives: how does the setting influence negotiation outcomes in an EU simulation?', European Political Science 14(3): 241-253.

Galatas, S.E. (2006) 'A simulation of the council of the European Union: Assessment of the impact on student learning', Political Science and Politics 39(1): 147-151.

Guasti, P., Muno, W. and Nieman, A. (2015) 'Introduction - EU simulations as a multi-dimensional resource: From teaching and learning tool to research instrument', European Political Science 14(3): 205-217.

Jones, R. and Bursens, P. (2015) 'The effects of active learning environments: How simulations trigger affective learning', European Political Science 14(3): 254-265.

Jozwiak, J. (2012) 'Vegelate' and Greece: Teaching the EU through simulations', European Political Science 12(2): 215-230.

Kaunert, C. (2009) 'The European Union simulation: From problem-based learning (PBL) to student interest', European Political Science 8(2): 254-265.

Kolb, D. (1984) Experiential Learning. Experience as the Source of Learning and Development, Englewood, NJ: Prentice Hall.

Raiser, S., Schneider, A. and Warkakka, B. (2015) 'Simulating Europe: Choosing the right learning objectives for simulation games', European political science 14(3): 228-240.

Raymond, C. and Usherwood, S. (2013) 'Assessment in simulations', Journal of Political Science Education 9(2): 157-167.

Switky, B. (2004) 'The importance of voting in international organizations: Simulating the case of the European Union', International Studies Perspectives 5(1): 40-49.

Usherwood, S. (2014) 'Constructing effective simulations of the European Union for teaching: Realising the potential', European political science 13(1): 53-60. 
Usherwood, S. (2015) 'Building resources for simulations: Challenges and opportunities', European Political Science 14(3): 218-227.

Zeff, E.E. (2003) 'Negotiating in the European Council: A model European union format for individual classes', International Studies Perspectives 4(3): 265-274.

\section{About the Author}

Sandra Kröger is a senior lecturer in the politics department at the University of Exeter. Before joining Exeter, she was a lecturer at Bremen University. Her research focuses on different forms of political representation in the European Union, particularly by national parliaments and by civil society organisations. She has published widely on the topic and also is the convenor of the ECPR Standing Group on Political Representation. 